\title{
Use of Space Syntax Technique to Improve the Quality of Lighting and Modify Energy Consumption Patterns in Urban Spaces
}

\author{
Maryam Kazemidemneh $^{1}$, Mohammadjavad Mahdavinejad ${ }^{2}$
}

\begin{abstract}
Urban lighting is one of the significant issues that urban designers and architects are facing, and it has received a special attention in recent years. Urban lighting pursues critical goals such as preserving the livability of the city during nighttime, providing a sense of security, maintaining the city's readability, etc. Use of incompatible patterns for lighting design wastes significant amount of energy annually. A master lighting plan for urban areas should be recommended to achieve these goals and prevent wasteful energy use in lighting. One of the solutions for designing an appropriate plan is to notice the pedestrian traffic pattern in the city by considering space syntax model and integration maps analysis. In this research, one of Tehran's regions has been chosen and its integration map has been generated using appropriate software. Tehran is selected as case study of this research while the results might be applied in other similar cities especially in developing countries. First, based on the integration degree of the passages which reveals pedestrian traffic pattern and considering recommended illuminance standards, the average required lighting has been determined. Second, comparing the measured lighting intensity and the standard amounts reveals the correlation between the presented urban lighting and energy consumption model. Eventually, different solutions for appropriate urban lighting design based on acceptable energy consumption patterns have been suggested.
\end{abstract}

Keywords: lighting design, space syntax, integration analysis, energy consumption, Sustainable Development

\section{Introduction}

Urban lighting is one of the significant issues, facing urban designers and architects, which have received particular attention in recent years. Masses, enclosed spaces, colors and texture of objects are only understood correctly when they have well lit and designers are always looking for a method to show the city at night, same as a day. One of the first goals of lighting is to increase the people's hours of activity, so that people can continue their activities after sunset [4]. Other significant goals such as creating security and maintaining the city's readability and creating an exciting atmosphere for citizens can also be considered for the significance of the urban lighting. Considerable thought in here is attention given to the pattern of energy consumption in urban streets beside the attention given to urban lighting objectives. Always a lot of energy is being used for the urban lighting and according to the world's statistics, twenty or thirty percent of consuming energy is wasted and does not play a role in urban lighting.

| ${ }^{1}$ Master of Architecture, Department of Architecture, Faculty of Art and Architecture, Tarbiat Modares, University, Tehran, Iran.

${ }^{2}$ Associate Professor, Department of Architecture, Faculty of Art and Architecture, Tarbiat Modares

University, Tehran, Iran 
One of the important issues facing designers for saving energy used for urban lighting is to pay attention to the principles of urban lighting. For this reason, indicators and standards for street lighting should be considered. For example, lighting in those parts of the city which are more important in terms of riding and pedestrian trip rate should be more than those parts that are less used. Global standards have specified the minimum lighting for urban roads. Here, we should look for a method for lighting the urban passages in such a way that they will be in accordance with international standards of minimum lighting, based on the vehicle and pedestrian movement and accordingly, the amount of energy lost in this area is reduced.

Consequently the principal here is finding the right relationship between the social behavior pattern of people in the city at night and spatial configurations. By increasing the complexity of the factors involved in human communication and the structure of artificial environments, such as urban spaces and architecture, the use of intuitive and narrative methods alone does not meet the needs of today's society [11]. One of the preceding methods is the use of space syntax techniques. In this technique, we seek to transform the form and spatial configuration, through mathematical language, into social processes such as pedestrian movement patterns [14]

\section{Research scope and procedure}

Consequently, in this research it is intended to use the space syntax technique to reach the pedestrian movement pattern and then classified crowded urban roads and compares this category with the global lighting standards, to suggest an appropriate energy consumption pattern for urban street lighting. For this reason, one of the old and crowded areas in Tehran has been chosen and through the specialized software of space syntax, we have outlined the pedestrian movement pattern. Then, this classification is compared with the recommended illuminance standard and then three streets were respectively chosen (crowded, average and quiet) and we have extracted the lightening of these streets. In the next step by comparing these results and the recommended illuminance standard, we will reach the amount of the energy lost and finally, we can get an appropriate lighting pattern for Tajrish area. In the end, this method can be generalized and developed into a suitable model for urban lighting. In order to better understand the topic, the process is shown in Figure 1. 


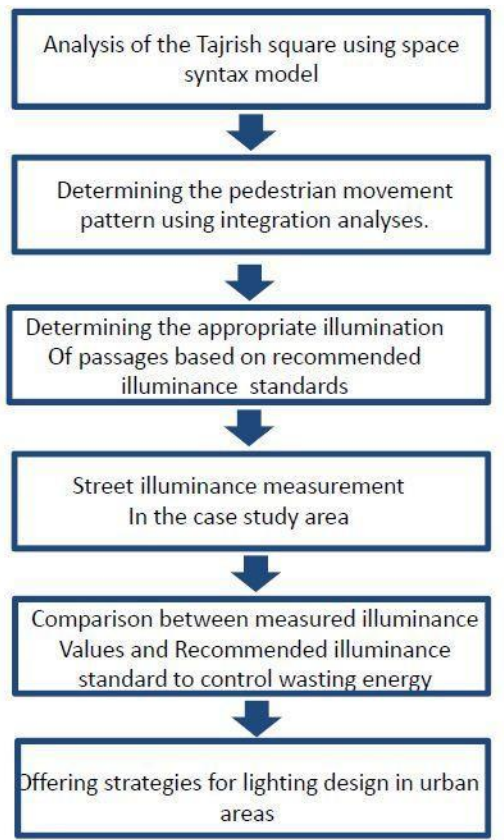

Figure 1: research scope and procedure

\section{Background}

\subsection{Space syntax theory}

Hillier and Hanson published a syntactic theory for the pattern of space and interaction in the built environment in the social logic of space in 1984. One of the foundations of space layout is the existence of a two-way relationship between space and socio-cultural patterns, in which this method is trying to explore it by using the concept of composition in urban spaces. In this sense, the shape of cities is a reflection of the citizen lifestyle and cities can be defined in the historical, economic, social and cultural aspects of people's behavior [8]. Space is a form that is shaped by social action and at the same time puts preconditions for social action. In the opinion of many scholars, spatial forms and social processes are different ways of thinking about a single subject $[5,10,13]$. Hiller believes that spatial and social forms follow such a close relationship that the spatial configuration by itself can define many social patterns such as land use distribution, movement, crime, immigration locating, and so on [7]. This theory states that before any other feature of space, such as form, shape, color, texture, etc., which are the characteristics of each space, those things that affects how space are experienced, is the relationship between spaces, known as spatial configurations. In fact, in this method, the characteristics of spaces are not individually significant in shaping the behavior of the users, as they are combined with other spaces in the system [2].

This theory believes that movement is essentially related to urban morphology and the major product of the space configuration and the method of communication between urban elements, so the spatial configuration alone can be 
considered as the main reason for predicting pedestrian movement [9]. This does not mean that the highest amount of movement in the city is due to spatial configurations, but it is confirmed that spatial configuration is the primary factor in creating the movement so that, without knowing it, it is not possible to study the pattern of movement in the city. Based on the theory in numerical terms, we can find a clear relationship between spatial patterns and how people use them. Using simulation and comparative comparison of the space syntax specialty software, the pattern of the combination of spaces and their relationship with the transformation into the desired graph has been analyzed and variables such as the degree of interconnection and separation are achieved this allows for the analyses of social-behavioral patterns. Space layout can be used to identify the most integrated and segregated spaces, so that pedestrian movement can be optimally managed [3]

The degree of integration is the mean depth that goes through the node to achieve all the nodes in the system. In the linear map we can say that the value of linking line or space is the average of the number of lines that can be accessed with it, from one line to the other lines of the whole system. The method of space arrangement, with the assist of the concept of integrated radios, can predict pedestrian movement. Experience has shown that the integration degree of a node is related to the rate of use of that node or the rate of pedestrian crossings in that node and this criterion is known as the potential of movement $[8,12,14]$. Integration has a communication concept in the space arrangement, not the concept of metric distance, In other words, the higher the integration rate of a street, the greater the pedestrian movement in it, and as a result space will be more favorable for the users.

Besides the concept of the potential of movement, there is another concept which is called the natural movement and it expresses the relationship between urban structure and the way urban spaces, which are located together with the pedestrian traffic density. Natural movement has another meaning, called movement economy. The natural movement and, as a result, the urban network, through the absorption of movement, will affect the patterns of use and the patterns of use will, after formation, intensify the natural movement. In this way, a cycle of aggravating impacts is formed, and this cycle will regulate the urban pattern [8].

\subsection{Correlation between lighting design and energy consumption}

Urban lighting design is a relatively new topic that has gradually entered the field of architecture and urban design. At the beginning of the entry into urban planning, the purpose of the designers was to create the city's security and lighting in order to expand the activity of the users at night. With the progress in lighting knowledge, other goals such as the beauty of the city at night, the identity of the city and creating security and maintaining the city's readability were also considered. And today's lighting performance is more than just lighting up the cities. The lighting needs to illuminate more than just the actual lighting functions; it also shapes the face of the street and defines the residential environment as a "homely" atmosphere [15]. Good lighting of a particular space can attract pedestrians to stop by and consider those objects in detail. It can 
affect the street in how it is perceived and used. Furthermore, it reveals the meaning of objects along the street, park and plaza including monuments and buildings and how those objects are perceived [10]. The importance of public environment lighting increases in a parallel way with the amount of pedestrian traffic in these places. Since the 1990s, along with an increasing concern with outdoor lighting, cities have started to glitter more at night [6]. The key issue here is the use of lighting techniques and methods in such a way that, besides creating a safe and suitable environment for pedestrians, they also control energy consumption.

Unfortunately, a lot of energy is wasted every year for city lighting. For example, according to estimates by the International Dark Sky Association, at least 30\% of the exterior lighting is being wasted in the United States, this waste of energy equals \$ 3.3 billion and produces 21 million tons of carbon dioxide per year, of this amount, 15 million tons of carbon dioxide is produced only from outside lighting of residential areas. To compensate for this amount of carbon dioxide,

875 trees should be planted annually. Also, according to the statistics provided by the Ministry of Energy in Iran, each year, 4,305,000,000 $\mathrm{kWh}$ of electricity is sold by the Ministry of Energy for street lighting, of which about $30 \%$ of this energy is wasted. The amount of energy lost is about

1.291.55000 kWh. This amount of energy dissipation is approximately equivalent to 23 million barrels of crude oil.

\subsection{History of Tajrish region}

Tajrish is one of the oldest regions in Tehran. At first it was not part of Tehran and was considered as countryside out of Tehran. Increases in urbanism and expansion of cities have changed this region to one of the most crowded places in Tehran with lots of vital passages. One of these important passages is Valiasr Street which is important since Pahlavi era about 100 years ago.

There are some significant old buildings such as Bazar of Tajrish and Emam zade Saleh monument and new buildings such as Arg and Tandis shopping centers. Tajrish does not follow a modern urban grid and passages are not based on grids.

Tajrish is selected as a case study in this project because of the mentioned reasons. That is to say all of these features make this area to be crowded by both vehicles and pedestrians at night.

\section{Data collected}

\subsection{Local integration map of Tajrish area}

In this section, the axial map of part of the Tajrish area has been drawn into the AutoCAD software. The axial map is a simplified representation of the street network. Then we have inserted this axial map into the Ucl Depthmap software and then performed integration analyses on it. Integration of a point indicates the integration or segregation of a point from a general system or from a lower system. Spaces that have more compatibility with other spaces, are considered to have higher integration rate. On this map, the red lines show high-integrated roads with more pedestrian traffic. In other words, these lines represent the most accessible paths, and vice versa, the blue lines 
show the paths with the least amount of integration. Figure 2 shows the integration map of Tajrish.

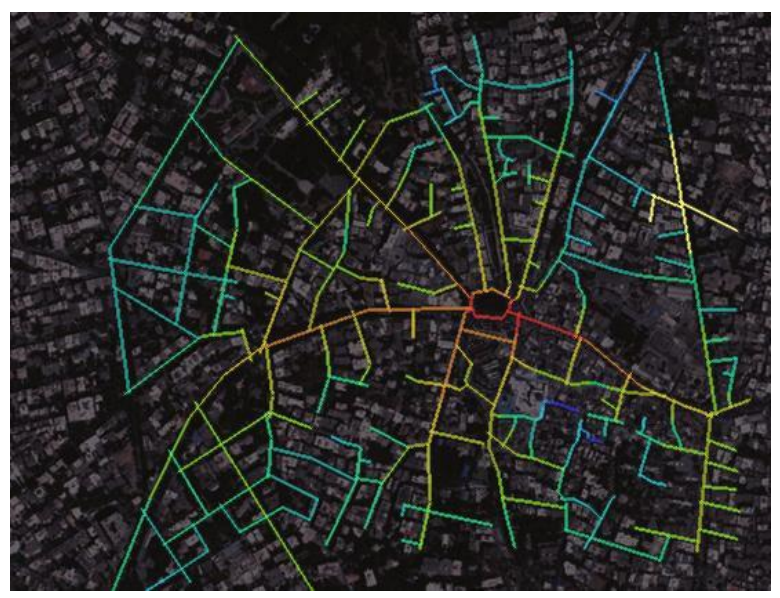

Figure 2: local integration map of Tajrish area

As it is clear, Tajrish square is among the most integrated places in this area and then two streets that reach the square. As mentioned before the higher the integration of a street, the greater the potential of pedestrian movement, as a result the space will be more favorable for the users. Of course, it should be noted that the natural movement, the movement resulting from the configuration of space, although is not necessarily the broadest movement in the city, it is the dominant movement in the whole city, so without it, most urban spaces are often empty [1]. According to the results gained from the degree of integration, we can categorize the paths in the map in terms of priority in lighting and the amount of lighting allocated.

\subsection{Standards of street lighting}

The outdoor lighting should support the design concept of the area and buildings, provide orientation and be comfortable. Especially for street lighting, quantitative aspects of light such as recommended illuminance, luminance, and uniformity of them should be verified and applied for both vehicle and pedestrians [1]. There are some classifications for streets for outdoor lighting purposes. Based on Iran recommended illuminance standard there are five types of road classification and for each of them three types of area classification contains of commercial, intermediate and residential. Table 1 shows the standard lighting intensity of each of these areas. 
Table 1: recommended illuminance level for different road types based on Iran recommended illuminance standard

\begin{tabular}{|c|c|c|}
\hline Description of road & Type of area & $\begin{array}{l}\text { Recommended illuminance } \\
\text { value-LUX }\end{array}$ \\
\hline High prestige roads & All areas & $6-8$ \\
\hline \multirow{3}{*}{$\begin{array}{l}\text { Heavily nighttime mostly use by } \\
\text { vehicle and pedestrian }\end{array}$} & commercial & $9-13$ \\
\hline & intermediate & $7-11$ \\
\hline & residential & $6-8$ \\
\hline \multirow{3}{*}{$\begin{array}{l}\text { Heavily nighttime use by vehicle } \\
\text { and pedestrian }\end{array}$} & commercial & $11-16$ \\
\hline & intermediate & $8-12$ \\
\hline & residential & $6-8$ \\
\hline \multirow{3}{*}{$\begin{array}{l}\text { Moderate nighttime use by } \\
\text { vehicle and pedestrian }\end{array}$} & commercial & $7-11$ \\
\hline & intermediate & $6-8$ \\
\hline & residential & $4-6$ \\
\hline \multirow{3}{*}{ Minor nighttime mostly use by } & commercial & $6-8$ \\
\hline & intermediate & $5-7$ \\
\hline & residential & $3-4$ \\
\hline
\end{tabular}

\subsection{Determining amount of lighting}

According to the pervious section we can extract the standard of lighting in passages based on pedestrian movement and traffic pattern. As an example streets with high degree of integration which are determined in red color consider more pedestrian movement in compare with the ones in blue. So it is better to consider their light intensity from 7 to 11 lux.

In order to analyze the lighting design of this area we have selected three passages as a sample to look at precisely.

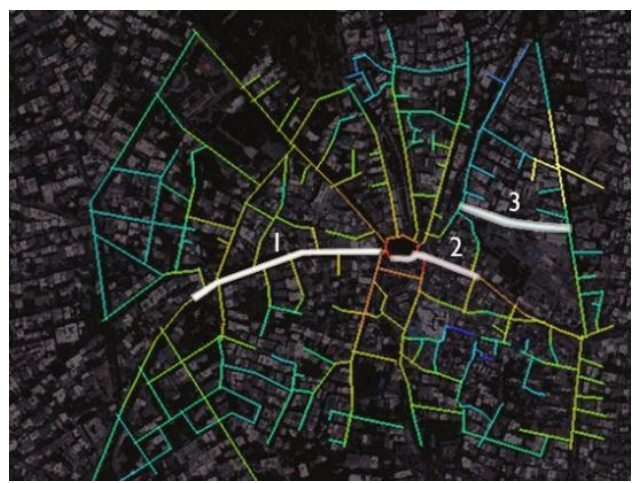

Figure 3: selected three passages in the case study area in order to illuminance measurement

(C) 2018 The Authors. Journal Compilation ～(C) 2018 European Center of Sustainable Development. 
Passage No1: Determining amount of lighting in the street footpath is measured by the Lux meter. The measurement method for lighting is shown in the figure in a schematic form.

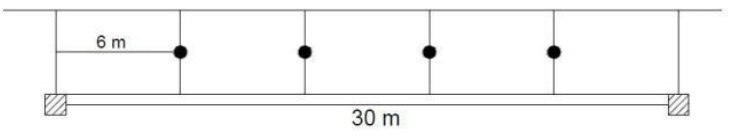

Figure 4: pattern of measurement of illuminance in selected street

The pedestrian street lights are at a distance of 30 meters and the base of the lights is 7 meters. Considering the relatively high pedestrian crossings of this path and according to Iran recommended illuminance standard, the proper lighting for this pathway is considered to be from

7 to 11 Lux. After tracking the path and measuring the lighting by Lux meter, the average lighting amount was 11 Lux. An important point here, is the lack of uniformity of the entire path. So that in the parts of the path the lighting amount was 16 Lux and in other sections 3 Lux was measured. The table shows the number of the measured values.

Table 2: measured illuminance values in street No 1

\begin{tabular}{|l|l|l|l|}
\hline \multicolumn{2}{|c|}{} & Measured illuminance-LUX & Recommended illuminance \\
\hline \multirow{4}{*}{ Light intensity } & minimum & 3 & \\
\cline { 2 - 3 } & average & 11 & $7-11$ \\
\cline { 2 - 3 } & maximum & 16 & .17 \\
\hline Uniformity & E min/ E max & .1875 & .33 \\
\cline { 2 - 4 } ratio & E min/ E ave & .2727 & \\
\hline
\end{tabular}

As it is shown in the table above, the uniformity ratio for this street is almost equal to the standard values. The overall uniformity ratio resulting from the least intensity of lighting division to the average lighting intensity, can be compensated by increasing the minimum brightness value.

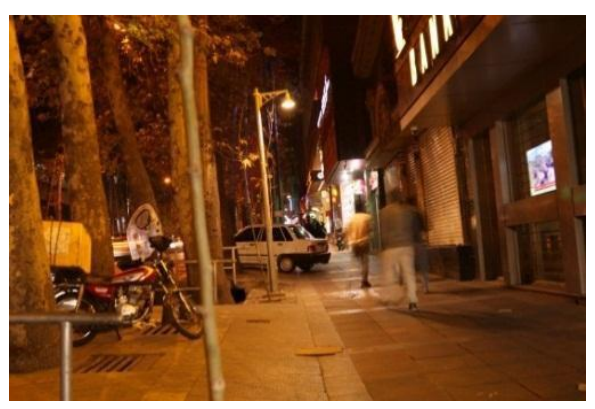

Figure 5: the measured lighting intensity of Street No 1 is around the standard amounts 
Passage No2: Parts of this path do not have an appropriate lighting conditions and part of the footpath is lit by the park lights next to it. Also, parts of the street are extremely bright and the reason is the extreme use of light bulbs at commercial sites. The other parts have light bulbs closer to each other than the previous passage.

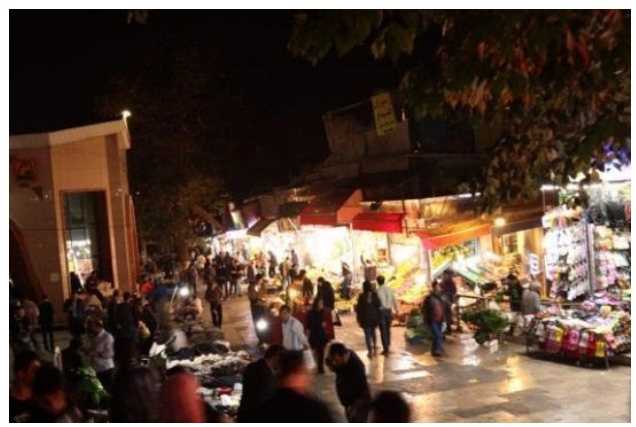

Figure 6: some parts of the street do not have street light bulbs, so the commercial areas are lit individually. The lighting intensity in these parts is measured 28 Lux.

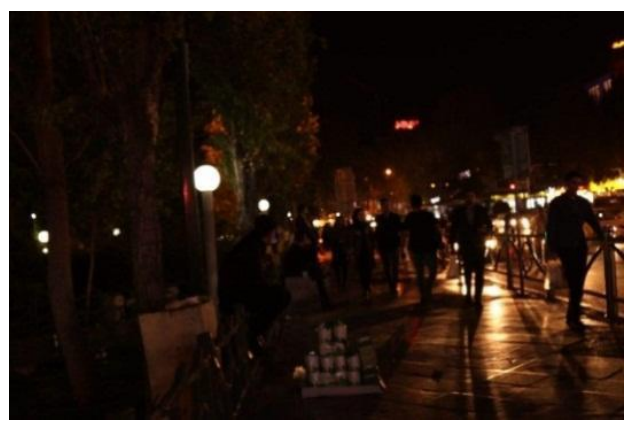

Figure 7: In some parts around the square there is not any specific light bulb and these parts are lit by park's light bulbs

Table 3: measured illuminance values in street No 2

\begin{tabular}{|c|c|c|c|}
\hline & & Measured illuminance-LUX & $\begin{array}{l}\text { Recommended illuminance } \\
\text { standard-LUX }\end{array}$ \\
\hline & minimum & 3 & \\
\hline Light intensity & average & 13 & $7-11$ \\
\hline & maximum & 28 & \\
\hline Uniformity & $E \min / E \max$ & .1071 & 17 \\
\hline & $\mathrm{E} \min / \mathrm{E}$ ave & .2307 & .33 \\
\hline
\end{tabular}

As it is shown in the table above, Due to the difference between the maximum and the minimum of light intensity, the uniformity ratio is less than the standard range. Also, the average lighting in this part is greater than the average lighting of path number one, because the lights in this range are closer to each other. 
Passage number 3: According to the integration map, this street is in blue and is not considered as a busy passage. By referring to Iran recommended illuminance standard, the amount of 5 to 7

Lux seems to be sufficient for this range. The table shows the number of the measured values.

Table 4: measured illuminance values in street No 3

\begin{tabular}{|l|l|l|l|}
\hline \multicolumn{2}{|c|}{} & Measured illuminance-LUX & Recommended illuminance \\
\hline \multirow{4}{*}{ Light intensity } & minimum & 3 & \\
\cline { 2 - 3 } & average & 10 & 5 to 7 \\
\cline { 2 - 3 } & maximum & 13 & .17 \\
\hline \multirow{2}{*}{$\begin{array}{l}\text { Uniformity } \\
\text { ratio }\end{array}$} & E min/ E max & .2307 & .33 \\
\cline { 2 - 3 } & E min/ E ave & .3000 & \\
\hline
\end{tabular}

As it is shown in the table above, the average lighting level is slightly higher than the standard level. The design of the lights in this street is similar to number one passage, but in terms of usage and volume of traffic is in the lower range. Therefore, it seems that choosing a type of design for two completely different passages cannot lead to a satisfactory result.

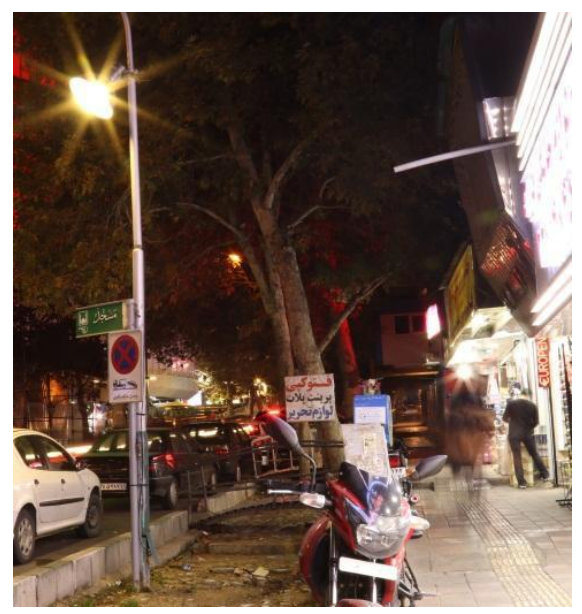

Figure 8: although street No 3 does not have high pedestrian traffic pattern, the lighting intensity is measured more than the standards.

\section{Data analyzing and proposals}

According to the measurements and tables presented, it seems that parts of the street lighting are in the standard range, and the other parts are not within range, which 
results in the loss of energy. In general, according to measurements, there are three different modes.

1) In parts of the passages the measured values are within the standard range. For sure, all of the lights in the study area have spent more than half of their life, therefore, it seems that at some point in time there was a loss of energy, because the lights of these passages are less lightening due to their half-life.

2) Parts of the passages have very low lighting intensity, this will make the problem in the pedestrian crossing areas, such as insufficient security for pedestrians. In addition, in this area, commercial places have to individually provide their own lighting requirements. This will cause light pollution and loss of energy. As in street No2, the intensity of the measured brightness was much higher than the permissible limit and the light intensity was measured about 28 Lux. Therefore, based on the volume of pedestrian traffic and by referring to integration analysis maps, this can indicate the standard range required for passages. In the second stage, selecting the appropriate light at sufficient distances and in general, lighting design engineering seems to be essential.

3) Parts of the passages have a higher brightness than the standard range. As mentioned above, to resolve this problem, it is better to determine the lighting intensity by the volume of traffic, which the one of the best way is to use an integration mapping pattern.

As mentioned before it seems necessary to extract pedestrian movement pattern in urban areas to estimate the required light intensity within the passages. The next step in lighting design is to determine an average lighting intensity for each area. Then the arrangement of lights is important. For example fixing the lights behind the trees can reduce the amount of received light.

\section{Conclution}

In this research, it has been tried to reduce the amount of energy losses in urban areas by providing a model for Urban and Street Lighting. Lighting can pursue many goals, such as maintaining city dynamism at night, creating readability, security, and so on. City at night should be illuminated in such a way as to provide security for the citizens, consequently a minimum lighting is needed throughout the city. But in areas where more people are present, attention to street lighting is more significant. In this regard, we should look for a way to prevent the loss of energy in these areas. Therefore, one approach could be a pedestrian traffic pattern implementation in the whole city. So that the axial map of these areas should be analyzed by the relevant software. Then, according to this roadmap, more accessible roads, and accordingly higher traffic and pedestrian capacity should be identified. In the next step, the lighting standard tables and the amount of light needed for the different integration ranges should be derived. This solution can be very useful for the urban master lighting plans and prevent macroscale energy loss. 
Future research can provide solutions to reduce energy dissipation in smaller quantities. It is very important to pay attention to the arrangement of the mounting lights in height, their distance to each other and also the clarity of the lights. The significance of mentioned factors is clear since they are parts of the parameters in measuring the illuminance formula. But in the way of the arrangement and installation of lights, features of the site should be considered. As an example, parts of the lighting lights available in passage No. 1 were hiding behind the trees. This caused the measured lighting in that area less than the average. In fact, after the presentation of the master plan for lighting design which can be done with the assist of the analytical integration software, the proposed design and implementation on a smaller scale can prevent energy loss in urban areas

\section{References}

[1]: An-Seop Choia, Young-Ook Kima, Eun-Suk Oha, Yong-Shik Kim. (2006). Application of the space syntax theory to quantitative street lighting design, Building and Environment, Vol. 41, pp. 355-366.

[2]: Batty, M. (2004). A new theory of space syntax, UCL Centre For Advanced Spatial Analysis Publications, CASA Working Paper, 75.

[3]: Bin Jiang, C Claramunt, Mike Batty. (1999). Geometric accessibility and geographic information: extending desktop GIS to space syntax. Computers, Environment and Urban Systems. Vol: 23 issue:2, pp 127146

[4]: Boyce Peter R. (1991). Security lighting: what we know and what we don't, Lighting

Magazine, No. 6, Vol. 5, pp. 12-18.

[5]: Dawson PC. (2003). Analyzing the effect of spatial configuration on buman movement and social interaction in Canadian Artic communities. Proceedings of 4th International Space Syntax Symposium, London

[6]: Fotios S. (2013). Maintaining brightness while saving energy in residential roads, lighting research and technology. Vol: 45 issue: 1 , pp: 7-21

[7]: Hillier, B.(2001), A theory of city as object, or, how spatial laws mediate the social construction of urban space, 3rd international symposim on space syntax,Atlanta.

[8]: Hillier B. (1996). Space is The Machine: a Configurational Theory Of Architecture, Cambridge University Press, Cambridge

[9]: Hillier B, Hanson J. (1984). The Social Logic of Space. Cambridge: Cambridge

UniversityPress

[10]: Loe D, Rowlands F. (1996). The art and science of lighting: A strategy for lighting design, lighting research and technology. Vol: 28 issue: 4, pp: 153-164, 1996

[11]: Patterson, J. (2016). Traffic modelling in cities - Validation of space syntax at an urban scale, indoor and built environment. Vol: 25 issue: 7, pp: 1163-1178

[12]: Penn, A. (2003). Space Syntax and spatial cognition - Or why the axial line? Environment and Behavior. Vol: 35, pp. 30-65,

[13]: Raford, N \& Ragland, R. (2003). Space syntax: an innovative pedestrian volume modeling tool for pedestrian safety, In: http://repositories.cdlib.org/its/tsc/UCB-TSC-PR-2003-11.

[14]: Raford N.(2003). Looking Both ways: space syntax for pedestrian exposure forecasting and collision risk analysis. Proceedings of 4th International Space Syntax Symposium, London, 2003.

[15]: Srisuwan A. (2012). Lighting Design in Public Urban Area in Reaching to Sustainable City: Case Study Jesi, Italy, Architecture and the environment, vol:21, pp 33-41 http://www.darksky.org/light-pollution/energy-waste/ 